\title{
Mindfulness Practice in Socially Engaged Ethnographic Fieldwork
}

\author{
Gene Ammarell \\ Ohio University \\ Athens, Ohio, U.S.A \\ Visiting Professor of Anthropology \\ Hasanuddin University \\ Makassar, Indonesia \\ ammarel@ohio.edu
}

\begin{abstract}
In recent years, the Buddhist practice of "mindfulness" has become the subject of research in the cognitive sciences and a potent tool in clinical psychology and counseling. While Buddhism, itself, is the subject of countless studies in the social sciences and histories of religion, there is a surprisingly small literature on the application of mindfulness practice in the social sciences in general and in ethnographic research in particular. This paper aims to begin to fill that gap by raising for discussion several ways in which mindfulness practice might be incorporated into ethnographic research and, in the process, increase the effectiveness of projects that are aimed, as is suggested by the theme of this conference, at "promoting social change for sustainable development goals." Drawing upon examples from my own research, I will show how mindfulness can help social scientists and development workers gain insights into the nature of social change and, consequently, become more effective as catalysts in enabling others as they seek a secure and sustainable future.
\end{abstract}

Key words-mindfulness practice; compassion; ethnographic fieldwork; engaged anthropology; social change; sustainable development

"You must be the change you want to see in the world."

"As human beings, our greatness lies not so much in being able to remake the world - that is the myth of the atomic age - as in being able to remake ourselves."

Gandhi's first rule for changing the world

\section{INTENTION}

I address you today as researchers who are working from across disciplines to combat social, economic, and environmental inequality and injustice and to enable communities to empower themselves and gain sustainable livelihoods, often in the face of overwhelming odds. My own experience and that of others with whom I have worked and whose writings I have read, has revealed to me that in spite of our best efforts, we often feel frustrated and may even experience burnout when, for any number of reasons, conditions do not appear to be improving. In our frustration, we may find ourselves reacting negatively toward ourselves and others; we may experience feelings of loss, anger, sadness, denial, and exhaustion... all feelings that are a normal part of being human but which can get in the way and make it even harder for us to be compassionate and effective as facilitators of change.

In this talk, I will touch upon some of my own frustrations as an ethnographer who quite naively stumbled into arenas of environmental and social injustice in a small maritime community in the Sabalana Islands of South Sulawesi. I will describe one of several cases of perceived injustice that I observed over the course of three decades of research and advocacy on the island village of Balobaloang. As I will explain, my responses to injustices, while well meaning, were not necessarily as effective as they might have been. I enter into this not to make excuses nor assuage any feelings of guilt or doubt. Rather, I intend to share with you some of the lessons I have learned along the way and to inquire as to how the practice of mindfulness, as I have experienced it, claims to offer a radical pathway to increased self-understanding which, when applied in the context of socially engaged fieldwork, may provide us new insights about our own roles as facilitators of change and, concomitantly, enhance our effectiveness, compassion, and wise discernment as we interact with individuals and communities in support of their efforts to reduce suffering and realize a greater sense of well-being in their lives.

It was through my introduction to mindfulness through cognitive science and psychology that I began to see strong connections between my work as an anthropologist and mindfulness practice. I will begin this talk by naming several of the basic concepts that have informed the discipline of cultural anthropology since it beginnings in the early $20^{\text {th }}$ century. I will then outline some of the fundamental understandings of mindfulness practice as I understand them. This will be followed by an example from my own fieldwork where a more mindful approach might have proven more effective in bringing the stakeholders 
together to resolve their conflicts. I will conclude with a discussion of how, through teaching and the study of mindfulness, I came to understand how an ethnographer, like myself, might go about incorporating mindfulness practice and act as a catalyst in socially-engaged research.

\section{KEY CONCEPTS IN CULTURAL ANTHROPOLOGY}

\section{A. Culture}

Culture is the core concept of cultural anthropology. That said, the idea of culture has always been highly contested. One textbook defines culture as the "set of learned and shared behaviors and ideas and practices that human beings acquire as members of societies." [1]

Up through the late $19^{\text {th }}$ century, the word "culture" was understood as the provenance of members of upper class European societies: the rest of the world, it was believed, needed to be "taught culture," i.e. European culture. Early in the $20^{\text {th }}$ century, however, there began to emerge a resistance to this paradigm among some European intellectuals, most notably Franz Boas and Bronislaw Malinowski, who, in the process of carrying out the first intensive ethnographic fieldwork, came to the conclusion that no one "culture" was inherently superior to any other; each had evolved as creative responses to social, psychological, physiological, and environmental, and historical factors, and each was to be treated with equal respect.

I want to emphasize that these ideas did not arise sui generis. Rather, they entailed a radical shift in consciousness that emerged from the direct experiences of thoughtful individuals working, for the most part, with marginalized peoples. Such transformations of consciousness, I will suggest, are available to all of us through an engaged mindfulness practice.

\section{B. Cultural Relativism}

This idea of the inherent value of all cultures that dominated much of the $20^{\text {th }}$ century led to the understanding that ethnocentrism might be best combated by cultural relativism. Again borrowing from Shultz and Lavenda, "ethnocentrism" may be defined as "the opinion that one's own way of life is natural or correct and, indeed, the only way of being fully human". Along with racism, sexism, religious fundamentalism, and extreme nationalism, ethnocentrism has a long and destructive history in human affairs.

Likewise, the goal of cultural relativism may be defined as coming to understand "another culture in its own terms empathetically enough so that the culture appears to be a coherent and meaningful design for living." [1]. Used as a research tool by cultural anthropologists doing ethnographic fieldwork, it is argued that cultural relativism is, more broadly, an important concept available to all who wish to reduce our own learned ethnocentrism. Perhaps the most challenging part of the practice of cultural relativism is the suspension judgment when we come into contact with culturally informed beliefs and practices that are contrary to our own.

Importantly, cultural relativism does not ask us to abandon our own beliefs and values nor are we asked to condone the injustices perpetrated by others, for example, those who mobilize culture (e.g., religion, ethnicity, and gender) as a way to gain and maintain power over others. It does mean, however, that through the suspension of judgment and exercise of empathy, we may come to make sense of "the behaviors, ideas, and practices" of others that otherwise are outside of our own worldviews and, thus, are initially opaque to our own understanding.

\section{The Social Construction of Culture}

In the process, as we build our own web of relationships with others, we begin to see and denaturalize our own culturally-conditioned ideas and practices, our internalized world view, what Pierre Bourdieu calls our habitus, and may come to the realization that all world views are and always have been socially constructed, that they are real but not true, and that our attachments to our own world views as somehow superior and universally correct are the source of our sense of separateness from ourselves and others, and, hence, our inability to build relationships based in mutual compassion and respect.

Thus, anthropologists attempt to practice cultural relativism as we conduct ethnographic fieldwork, observing and participating in the lifeways of others. The overall purpose of our work is to explore who we are as human beings and why we do what we do as members of particular social groups. Moreover, we communicate our findings in an effort to increase respect and understanding across cultures and societies and to see the fundamental and inextricable connectedness of all of humanity and the environment upon which we depend for our lives and livelihoods.

\section{Ethnographic fieldwork as an "intersubjective" conversation}

Although the world continues to suffer under the afflictions caused by the objectification of the cultural "other," anthropologists have increasingly turned away from pretentions to objectivity, recognizing the limits of our authority in our written and visual representations as well as our responsibility to engage, as fully as possible, the subjects of our investigations in our studies.

Thus, as anthropologist Paul Rabinow argues, ethnographic fieldwork is no longer a one-way street. Rather it is the process of building a bridge between anthropologists and cultural others so that each can begin to understand the other, and where cultural others and cultural selves are understood as simultaneously creators and created in the process of their interactions. Citing Paul Ricouer, Rabinow suggests that the task of ethnographers is one of interpretation by which we come to comprehend the culturally constructed and historically situated self by the detour of comprehending the cultural other. This shared experience results in new knowledge about the informant's 
culture that is mutually meaningful; a hybrid product of common understandings that emerges through the collaboration of the ethnographer and the informant [2]

\section{E. Power, Privilege and the "Compassionate Turn" in Anthropology}

While ethnographic fieldwork, as understood by Rabinow, is a mutual conversation between the ethnographer and members of the community under study, it is vital to add that it must not ignore the asymmetries of power in that conversation: most often the researcher is in a position of privilege relative to community members in that the researcher will eventually leave the research site and, thus, not have to live with the consequences of his or her interactions.

Moreover, our engagement with communities inevitably enmeshes us in the lives of others such that we cannot ignore their oppression and suffering. It is in this regard that what Robben and Sluka term the "compassionate turn in anthropology" that emerged in the last decade of the $20^{\text {th }}$ century [3] While the compassionate turn is seen by the authors in a number of approaches, the "common denominator is the importance of empathy both as a methodological technique to grasp the Malinowskian native point of view and as an epistemological approach to understand people's subjectivity. Such empathy turns to compassion when the ethnographer has a clear awareness of the moral, ethical, and political implications of the ethnographic knowledge. Practitioners become implicated in the lives of their research participants, engage in social advocacy as witnesses, or, ...bring their scholarly expertise to current events. They try to influence public debates and at times encourage social and political changes that will lessen the violence and suffering inflicted on societies...." [4]

The turn toward such compassion in ethnographic fieldwork, I will argue, creates a fertile ground for either ineffectual reactivity or greater clarity, opening up a space in our minds in which we can see more clearly and, thus, bring greater wisdom and efficacy to our decisions and actions.

\section{MINDFULNESS AND ITS PRACTICE: DON'T GET ATTACHED TO A BALLOON!}

In this section, I turn attention to the nature of mindfulness and its practice as I understand it, emphasizing how the practice of mindfulness may transform and enhance such engagement to the benefit of all.

In Buddhist philosophy and practice, mindfulness has long been adhered to as a way for practitioners to relieve suffering and dispel illusion in their lives. In the cognitive and behavioral sciences and clinical psychology it has developed into a secular practice aimed at, among other things, the alleviation of stress and its debilitating effects in people's lives. From there it has been adopted and adapted across multiple domains of human experience.

Here I will define mindfulness as "the moment-tomoment awareness of all that we individually experience through our senses of touch, taste, hearing, sight, and mind."
So defined, mindfulness is cultivated though a practice of purposely paying attention to that which we, as sentient beings, experience as we experience it.

For most of us, this is a fairly radical departure from how we experience the world and ourselves. More often, we find ourselves caught up in our thoughts about the past and future accompanied by feelings of aversion to that which we perceive as unpleasant and attachment to those things we perceive as pleasant. Thus, as if in a trance, our minds are so busy with thoughts and feelings that we miss the reality of the present moment, whether a beautiful sunset or a car about to run into us.

\section{A. Impermanence and Attachment}

So to, we easily get stuck in our attachments and aversions, forgetting that all that we experience, even life itself, is temporary. One of the firsts lessons about impermanence and the futility of attachment many of us learned as children was not to get attached to balloons, as they inevitably burst or shrink to lifeless pieces of rubber. While intellectually we easily recognize the impermanence of all things and that the universe, including we ourselves, are in a constant state of flux, we still unconsciously cling to things, including everything from our material possessions to our own thoughts and beliefs, as if they were exempt from the truth of impermanence. Through mindfulness practice, however, begin to recognize this truth on deeper level of awareness.

\section{B. The Practice: Pausing}

When practicing mindfulness, whenever we notice ourselves unconsciously caught up in thoughts and feelings about the past or future, in particular when we are experiencing reactivity, we have the opportunity to pause and return to the present moment (in fact, the act of noticing is, in itself, a return to the present moment). As we practice the pause, we begin to see all that we experience, including our thoughts and feelings, as an impermanent, everchanging, moment-by-moment flow in which they arise/emerge and recede/pass. A common example is whenever we are eating and find ourselves distracted in our thoughts and, thus, not experiencing the tastes and textures of our food in the moment. We can choose to pause from out thoughts and simply enjoy each bite!

\section{Mindfulness and the Suspension of Judgment}

In common with the concept of cultural relativism and its intentional suspension of judgment in ethnographic fieldwork, mindfulness a tool by which we can investigate and deepen our awareness our own beliefs about who we are and how those beliefs inform our relationships with others. Put another way, mindfulness is a path that can free us from our reactivity by observing our own thoughts and actions as well as those of others without judgment or attachment. In fact, through mindfulness we begin to see ever more clearly the judgments and attachments to our own ideas and feelings that are ubiquitous in thoughts. 


\section{Reacting versus Responding}

Reactivity, itself, was selected for its survival value in animal as well as human populations. Based in the autonomic nervous systems, the "primitive brain," it causes us to react to dangerous situations in one of three ways: fight, flight or freeze. In fact, it has been shown that this reactivity begins even before the perceived danger enters our conscious mind. While this innate tendency to react is useful for short periods of time in critical situations, it also emerges in common, non-life-threatening situations, preventing us from responding in more thoughtful, calm, and constructive ways until and unless we can "calm down" by utilizing the parasympathetic nervous system.

The persistent pressures of life wires our brains to rely more and more on the autonomic nervous system and, thus, to react rather than respond in all sorts of situations. This reactivity in social situations often takes the form of judgment and criticism of the thoughts and actions of others and as often of ourselves, but it can also be directed at other phenomena over which we have little or no direct control [a flat tire, a toothache, a stock market crash, etc.] In such situations, we may find ourselves thinking "If only we/others or things were different than they are..." and we may even try to change them through actions ranging from softly suggesting to "reasoning" and from nagging to coercion. Or, from another angle, we are caught up in "should": "Things should be different." At those moments we are, in fact, waging a futile argument with the reality of how things are, at least in the present moment. In all these cases, we are reacting to what are, at least for us, moments of unpleasantness, as if we could change what just took place or what we are afraid might take place again in the future. The reality is, however, that we cannot willfully change others' beliefs or their actions, at least through our own reactivity. In short, when it comes to trying to change ourselves and others, "resistance leads to persistence" as we tend to react to the reactivity of others through entrenchment.

\section{E. "Neurons that fire together, wire together"}

For those of us who feel more or less fatalistic about our ability to actually make such important changes in our lives, the good news is that we can train our brains - actually rewire them - to respond "mindfully" when we feel attacked or under pressure, that is, with openness and with compassion for ourselves and others. Recent studies in the fields of psychology, neurology, and contemplative neuroscience demonstrate that our brains are highly plastic and our minds and our brains are routinely changing one another. Our thoughts and feelings, over time, leave lasting changes in our brains, or as psychologist Donald Hebb puts it, "Neurons that fire together, wire together." Thus, through the practice of mindfulness, we can rewire our brains, diminishing our reactivity as we actively entertain more positive feelings about ourselves and others.

\section{$F$. Deconstructing our own worldviews: real but not true}

The goal of mindfulness practice, then, is to train ourselves to increasingly live in the present moment, fully aware of our thoughts and feelings as they arise and subside, such that we can consciously respond, not unconsciously react. In doing so, we clear our minds of the "noise" that interferes with making wise and ethical decisions and actions, and we become more conscious of the mental formations and constructs, the social and cultural conditioning, that limits our view of ourselves and the world and, thus, our creativity and the range of possible choices that we can make. We begin to see we have internalized and reified our beliefs and opinions, clinging to them and taking them as true.

As human beings, it is all too easy to take our beliefs and opinions seriously, even dogmatically such that we come to embrace them as universally true. However, real they are, they are, in fact, no more true than the beliefs and opinions of others, whether they be colleagues or participants in ethnographic research or development projects. Clinging to them, we are blinded to the beliefs and opinions of others and, thereby, cut off from what might be more creative and sustainable solutions to problems. Concurrently, we tend to elevate our own ideas and beliefs above those of others, thereby creating separation rather than connection. Mindfulness, thus, is neither an abstract notion nor is it an ideology; rather it is a practice that promises to release us from the oppression of our own dogmatic and ideological beliefs, freeing us to connect with others in a more compassionate and open manner.

\section{F. Easy to grasp, hard to do: the "second arrow" of self- judgment}

It is important to note that mindfulness, while fairly simple to grasp conceptually, is quite difficult to carry out both formally and informally. One of the basic exercises in formal practice is simply paying attention moment to moment to sensations of the breath, either noticing the sensation of air passing through the nose or the expansion and contracting of the lungs and diaphragm as we breath in and out. This exercise in concentration seems simple enough, but for most of us it is quite difficult to sustain concentration on the breath for more than a few breaths at a time before thoughts and feelings creep back in to our minds. These interruptions are perfectly normal and allow us to immediately explore some important things about ourselves. That is, do we accept these interruptions and carry on with the exercise, or do we react to them with self-criticism and self-doubt? Such reactivity is likened to a "second arrow" with which we shoot ourselves when we react with aversion or attachment to the physical and emotional pain that all human beings experience in the course of our lives.

Of course, we will all experience many "first arrows"; they are unavoidable. The critical question concerns how we deal with that pain; do we "react" with self-criticism and doubt about our own ability - the second arrow - or do we "respond" with acceptance and equanimity? Even if you find yourself continually loosing your concentration and then falling into self-judgment, the good news is that the moment you realize you are judging yourself, you are back in the present moment. But, if you find yourself congratulating yourself for holding your concentration, you have fallen out of the present moment, that is, until you recognize that you 
are congratulating yourself! If all of that sounds confusing, just remember that the practice is just that: a practice in which we watch for the second arrow of reactivity in any situation, recognize it for what it is, and move on. Just this can have the long-term effect of freeing our minds and helping us to see what is present to us in each moment and accept it as the only "now" that is possible - otherwise it would be different!

If, however, we are to accept each moment as it is, how can we stand against injustice and the suffering of others and ourselves? The answer is that to the extent we can see injustice directly, unencumbered by our own beliefs and opinions, our attachments and aversions, we can respond more effectively and with greater compassion to the suffering of others. Or as Gandhi was quoted as saying, "You must be the change you want to see in the world."

\section{A REFLECTION ON REACTIVITY AND ATTACHMENT IN MY OWN FIELD RESEARCH}

As a self-proclaimed socially and environmentally engaged anthropologist, my introduction to the field began with my purely intellectual curiosity about the diversity of human conceptualizations of the natural environment across cultures, beginning with the celestial sphere of sun, moon, stars, and planets. This led me to the study of indigenous knowledge and practice of navigation among Bugis seafarers from the island of Greater Balobaloang located about 112 nautical miles SSW of Makassar, South Sulawesi. As I was winding down my dissertation research on navigation in early 1992, I was alerted to the fact that the reef around the island which villagers had fished for generations was being invaded by commercial fishermen from other islands, both near and far, who used explosives and cyanide poison to rapidly capture large quantities of fish, and, in the process, causing significant damage to the reef and, thus, the fishery itself. From that time and during subsequent visits I witnessed the rapidly increasing destruction of the reef accompanied by a dramatic decrease of fish stocks, jeopardizing the lives and livelihoods of villagers.

\section{A. Engaged Research on Destructive Fishing Practices}

In 2003 I returned to Balobaloang to learn more about the fishery and the traditional and more sustainable practices used by local fishers. Early on, I discovered that the fishers, themselves, had been trying to curb the illegal and destructive practices of the outsiders, including burning a fishing boat belonging to a repeat offender, but their efforts had been in vain due to a chain of corruption and collusion that involved the bosses of the illegal fishing fleets, government-assigned police and military officials, and village chiefs [5]. As I observed and fished with local fishermen aboard their boats and conducted interviews both on and off of the water, the complexity of the problem began to emerge.

What became apparent was that corruption of officials, strong ties of kinship, and traditional patron-client relationships between the village head (and some ship owners) and the fishermen prevented the fishers, who depended upon the largess of the wealthy, from speaking out and challenging the status quo. The fishers were clearly aware of the disastrous impacts of blast and cyanide fishing on the fishery, but they felt helpless to do anything to stop it. On my part, I was feeling increasingly frustrated that what looked like an "obvious" problem could be so intractable. Even so, I did my best to support local efforts to curb the blast and cyanide fishing, responding to their requests to use whatever political capital I had as foreign researcher to advocate on their behalf, that is, to educate government and police officials on the mainland and, presumably, to move them to action.

\section{B. "Sharing Paradise: A Participatory Video}

After I had laid the groundwork, several graduate students from Ohio University and Hasanuddin University joined me for two projects: mapping the condition of the reef and producing a participatory documentary film. While the subject of the film was left up to villagers, the majority of those present at meetings voted to focus on fishing and the destruction of the reef. Amelia Hapsari, the filmmaker, is a native of Semarang, East Java, who studied visual communication at Ohio University. As an ethnic Chinese working in a rather conservative Bugis-Makassar village, she overcame deep-seated negative stereotypes to gain the respect and cooperation of villagers. It was her willingness, in the end, to travel aboard local fishing boats in choppy seas to capture photographic evidence of blast fishing that convinced villagers that she was serious about trying to help them get the message to government officials about their plight and that of the reef. In addition, she was able to gain access to and interview the complicit village head and blast fishers from a nearby island, something I had thought to do but had put off, caught up in my own reactivity. While Amelia had the temperament and training of a good investigative journalist to draw people out and even to challenge them albeit respectfully, I found that I was too wrought with judgment and anger to attempt to do likewise.

\section{Reactivity obstructs engagement: a missed opportunity?}

A good example of my reactivity follows. Not far from our house, there was a still-undisturbed patch of coral that I often visited and even photographed featuring a large and quite old table coral. One morning from inside the house, I heard the loud blast of a bottle bomb and went outside to observe the scene. A neighbor pointed in the distance to the perpetrator's boat that, I noted, was very close to the table coral. In a rage, I ran to the shore and jumped into a dugout while my wife yelled at me, "Don't get yourself killed!" I paddled out, waving my paddle and yelling at the men on the boat, warning them that if they didn't clear out, I would bring the Coast Guard (Polair) in and have them arrested. They did leave, but only temporarily, and I did report the incident, but to no avail.

\section{Voice given but ignored}

At the request of villagers, Hapsari showed footage of a bombing in progress and local reactions to the problem to the Bupati (regent) of Pangkajene dan Kepulauan Province and 
officers of the South Sulawesi Polair in Makassar who expressed their concern but also their relative powerlessness to stop the destruction: they simply didn't have the material resources to police the vast area of coral reefs. Only the villagers themselves, to paraphrase the bupati, could resolve the problem. This was not a new idea; we had already discussed the idea with some of the participants in the study of working together with the perpetrators and their families to create more sustainable livelihoods for all, but clearly I was not equipped to lead this conversation, and it never came to pass.

\section{E. A last minute attempt at dialogue}

Before I left the field, I did, however, decide to make a last-ditch attempt to reach out to villagers on the nearby island where Hapsari had successfully carried interviews with blast fishers. In an effort to open dialogue, I traveled to their island to show an early version of Hapsari's film and to record their comments. This attempt, I now understand, was ill fated: villagers knew my reputation as judgmental and even confrontational, and might have correctly guessed that I still wished to show members of the community "the error of their ways." In the end, they could see what I could not, and there was no dialogue: community members stayed away and only one small child and an old man came to view it.

\section{F. Learning from teaching}

When I returned to teaching at Ohio University, I continued to ponder the problem, but I gained little clarity as to what was really going on that such an injustice should persist. It took, however, several years before I would begin to understand how important is the suspension of judgment in ethnographic research, how difficult it was for me, how it can lead us to deeper insights about others, and ourselves and, thus, how we might become more effective in our work.

On campus, a new graduate student, Mohammed Chozin, became interested in my work. Coming from a Javanese fishing village, he proposed to carry out his thesis research on an island near Makassar that was populated by fishing families who relied almost exclusively on blast fishing to support their families. The result of his research is a published thesis that is, perhaps, the most detailed account available of both the expert knowledge and practice of blast fishing and the social lives of the villages that are supported by it. Importantly for me, it serves as an outstanding example of the rapport we can build and what we can learn by being open and respectful in our research, even when we find the activities of some of the participants to be morally offensive [6]

\section{$G$. The importance of the conversation itself}

Although I had often introduced students to Rabinow's argument that ethnographic fieldwork is fundamentally an intersubjective conversation, the importance of the conversation itself in fostering empowerment came to my attention in an article that I incorporated into my teaching written by anthropologist Rogaia Abusharaf.
In her effort to bring together women activists from across Africa to explore the issue of female genital mutilation "within its various cultural and historical contexts" both within Africa and in the diaspora, and the efforts of human rights activists to eradicate it, Rogaia Abusharaf edited a volume whose intention is to give voice to African women, respect "indigenous processes of social and cultural change, and show the connections "between respect for women's bodily integrity, the empowerment of women, and the democratic modes of economic development." In her introduction to the volume, Abusharaf discusses the historical and contemporary contestation that has surrounded the practice. Critical of previous studies that condemn the practices and see the women who experience these operations as "victims to be liberated," Abusharaf challenges us to respect them as agents who know best how to respond to these practices. In practice, she finds that what I have described as "paying mindful attention" is essential if we hope to effectively support our fellow human beings in their efforts to overcome injustice. To quote Abusharaf:

Careful listening to women helps us to recognize them as political actors forging their own communities of resistance. It also helps us to learn how and when to provide strategic support that would be welcomed by women who are struggling to challenge such traditions within their own cultures" [7]

In my reading of Abusharaf's approach to engaged fieldwork, I was (and remain) deeply impressed by her ability to suspend judgment and take on the highly emotional issue of female genital mutilation in her fieldwork. Certainly, my own history of reactivity to perceived injustice would have prevented me from even attempting such research. In my heart, however, I felt that she was correct: that only through the suspension of judgment and "careful listening" could we, as socially engaged researchers, hope to enable the empowerment of others. That is, the more mindfully we engage with others, the more space we give them to gain insights into the nature of their own oppression and how their own worldviews may contribute to, and/or inhibit, effective action. The more we can free ourselves from our own agendas, conscious and unconscious, the better able we will be to support others as they work to create their own agendas for change.

\section{THE SOCIALLY ENGAGED RESEARCHER AS CATALYST}

To the extent that ethnographic fieldwork is fundamentally an intersubjective conversation based in respect for the fundamental dignity and agency of those with whom we interact, my own perception is that the conversation itself becomes a catalyst for personal and social change and empowerment for all those who participate. From the viewpoint of mindfulness practice, for those of us whose intention is the improvement of the human condition through active engagement with disempowered communities, this understanding of our role as one of catalyst is, perhaps, the most honest, realistic and effective vantage point from which we can approach our work. That is, the more mindfully we engage with others, the more 
space we give them to gain insights into the nature of their own oppression and how their own worldviews may contribute to, and/or inhibit, effective action. The more we can free ourselves from our own agendas, conscious and unconscious, the better able we will be to support others as they work to create their own agendas for change. In this sense, what we can contribute to the empowerment of others emerges from a sincere respect for the dignity and freedom of others to make their own choices given the limitations that exist in their world. As a practice, it entails deep listening, paying attention, and concentrating our awareness moment to moment, that is, being mindful of others with whom, after all, we are inextricably connected in our common humanity.

In retrospect, then, it was my own reactivity that prevented me at the time from being able to listen without judgment to the stories of those directly or indirectly involved in the blast and cyanide fishing as well as seeing my own thoughts and beliefs and those of others to be what they were: only ideas, real but not true. On one hand, we did try to respond the requests of villagers through the reporting of illegal fishing and the production of a video that would give voice to their concerns. On the other hand, I ask myself if a more mindful approach might have been more effective in enabling dialogue among the stakeholders and catalyzing constructive change. Moreover, I wonder how my reactivity might have negatively impacted the very people I was trying to empower. Of course, I cannot answer this and I try not to dwell upon it. I am, in the writing of this paper, simply viewing it as an opportunity to learn about my own mind and how my own thoughts and beliefs affect my work.

Soon I hope to return to Balobaloang to learn more about what has transpired since my last visit several years ago. Even though I have studied and practiced mindfulness in the interim, I cannot be sure that my reactivity will reemerge if I find that the situation continues as before. All I can be sure of is my intention to practice mindfulness to the best of my ability as I engage once again with villagers and listen to their stories.

\section{REFERENCES}

[1] E. Schutz and R. Lavenda, Cultural Anthropology: A Perspective on the Human Condition, 7th ed. Oxford University Press, 2008.

[2] P. Rabinow, Reflections on Fieldwork in Morocco. University of California Press, 1977.

[3] J. Sluka and R. Antonius, Ethnographic Fieldwork: An Anthropological Reader,. Wiley-Blackwell, 2011.

[4] R. Antonius, What Anthropologists Can Teach Us about the War. Philadelphia: University of Pennsylvania Press, 2011.

[5] G. Ammarell, Just below the surface: Environmental destruction and loss of livelihood on an Indonesian atoll. Bloomington: Indiana University Press, 2011.

[6] M. Chozin, Illegal But Common. VDM Verlag, 2009.

[7] R. Abusharaf, Female Circumcision: Multicultural Perspectives. Philadelphia: University of Pennsylvania Press, 2006. 